PR-5

\title{
DESIGN, SYNTHESIS, CHARACTERIZATION OF GEMINAL BISPHOSPHONATES AND BIOACTIVITY EVALUATION
}

\author{
C. Bhupendra Reddy, ${ }^{1}$ N. Bakthavatchala Reddy, ${ }^{2}$ C. Naga Raju ${ }^{1 *}$ \\ ${ }^{1}$ Department of Chemistry, Sri Venkateswara University, \\ Tirupati-517 502, Andhra Pradesh, India. \\ ${ }^{2}$ Ural Federal University, Chemical Engineering Institute \\ Yekaterinburg, 620002, Russian Fedaration.
}

*Corresponding author e-mail: rajuchamarthi10@gmail.com \begin{abstract}
prevention and cure. In the cancer, chronicmyelogenous leukemia is one type. It is also known as chronic myeloid leukemia. It is a malignant cancer of the myeloid line of cells in the bone marrow that results in the uncontrolled growth of white blood cells in the bone marrow, bloodstream, and body tissues. The colorectal cancer is another type of cancer that occurs in the colon or rectum. Sometimes it is called colon cancer. Management of these cancers is highly difficult. In persuation of our goal to synthesise cancer active compounds, the author accomplished synthesis of substituted amino methylene bisphosphonates (3a-j) and studied their antitumor activity.

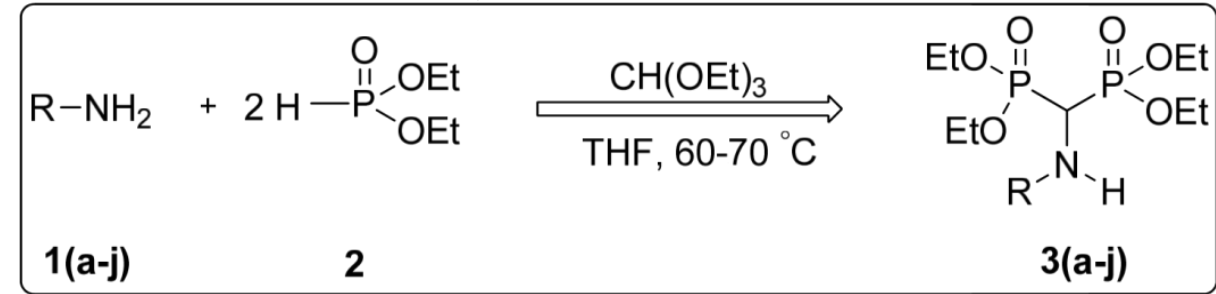

Abstract. Cancer is a deadly disease evading all human efforts to understand its etiology, 